\title{
MESTO PONOČI (NA PRIMERU MARIBORA)
}

\section{dr.Vladimir Drozg}

Oddelek za geografijo, Filozofska fakulteta Univerze v Mariboru

Koroška cesta 160, SI-2000 Maribor

e-pošta: vlado.drozg@um.si

Izvirni znanstveni članek

COBISS 1.01

DOI: $10.4312 /$ dela.45.3.49-64

\section{Izvleček}

Prispevek obravnava mesto v nočnem času. Posebnost obravnavane tematike je časovna razsežnost prostora ter območja - kraji, ki »živijo« ponoči. Noč ima ekonomsko, kulturno, oblikovno in socialno vsebino in prav te lastnosti določajo spoznavanje mesta v nočnem času. Izpostavljene so naslednje teme: kraji potrošnje, kraji dela, kraji zabave, kraji nočne podobe mesta ter kraji družbeno nesprejemljivega, delikventnega vedenja. Empirični del se nanaša na mesto Maribor.

Ključne besede: mesto, noč, kraj, čas, Maribor, Slovenija

\section{THE CITY AT NIGHT (THE CASE OF MARIBOR, SLOVENIA)}

\begin{abstract}
This paper focuses on the city at night. The distinctive aspect of the discussed topic is the time dimension of spaces and areas - places that "live" at night. The night has economic, cultural, social and formal elements; and it is these elements that underpin how we see and come to know the city at night. A range of topics have been explored: places of retailing and consumption, workplaces, places of entertainment, places that embody the night image of the city and places of socially unacceptable, delinquent behaviour. In the empirical part, we examined the city of Maribor, Slovenia.
\end{abstract}

Key words: town, night, place, time, Maribor, Slovenia 


\section{UVOD}

Noč je del dneva, ko ni naravne svetlobe, ko je sonce pod obzorjem, oziroma čas med sončnim zatonom in vzhodom. Dolžina noči se tekom leta spreminja, različna je tudi na geografskih širinah. Vmesni čas med svetlim in temnim delom dneva, večer oziroma mrak ter jutro oziroma zora, sta prehodni fazi, ki pa sta prav tako časovno spremenljivi - pozimi nastopita prej, poleti pozneje. Noči zato ne moremo točno opredeliti, saj se njihova dolžina spreminja. Takšno pojmovanje je iz naravoslovnega vidika najbrž povsem ustrezno. V družboslovju in humanistiki pa je razumevanje noči nekoliko drugačno. Noč je del dneva z močnim socialnim in simbolnim nabojem, ki se je oblikoval že pri najstarejših ljudstvih. Za večino ljudi je noč več kot le kozmični pojav. Noč je sinonim za strah, smrt, grozo, kaos, pregreho. O temnem delu dneva je nastalo veliko posebnih občutij, ki jih še danes nosimo v podzavesti. Kažejo se kot nelagodje, strah, pa tudi kot priložnost zaradi manjšega socialnega nadzora in omejenosti. Vendar noč nima samo negativne konotacije, ima tudi pozitivno. Noč je čas posebnih stanj in dejanj, ki so človeku še kako pomembne - počitek, intimnost, mir, spokojnost, pa tudi zabava, sprostitev in socialno življenje. Številne dejavnosti na večer zamrejo, vendar se pojavijo mnoge, ki so »noč zamenjale za dan«. Spremenijo se dejavnosti, ki jih počnemo, njihova intenzivnost ter kraj, kjer jih izvajamo. Opaziti pa je še en proces: vse več gospodarskih dejavnosti in vsakodnevnih opravil je mogoče opraviti v prvem delu noči, zgodaj zjutraj ali celo kadarkoli tekom dneva. Metafora o mestih, ki živijo 24 ur na dan, je sicer slikovita prispodoba, vendar zagotovo drži, da noč ni več izključno čas počitka in družinskega življenja. Ta pojav je posledica ekonomskih zakonitosti sodobnega kapitalizma in podaljševanja ekonomske aktivnosti, vse večje ponudbe vsega mogočega, pa tudi vse večje socialne diferenciacije, novih življenjskih stilov, prilagodljivega delovnega časa, novih socialnih omrežij. S tem povezana individualizacija je vzrok raznoliki ponudbi blaga in storitev - ena od oblik tega je širjenje dneva v noč. »Vse ob vsakem času« je geslo ene izmed številnih prispodob sodobnega življenja (Difu-Berichte ..., 2002).

Primerjava s prostorom morda ni povsem naključna: v preteklosti je dogajanje v prostoru označevala vse intenzivnejša raba, ekspanzivno širjenje, spreminjanje namembnosti, prenova, drobljenje in razkosavanje. Danes se podobno dogaja s časom - postaja vse bolj omejena dobrina, vse več časa namenimo delovanju z ekonomskim učinkom, dejavnosti so vse bolj časovno zgoščene in intenzivirane, stvari se odvijajo vse hitreje, meja med prostim in delovnim časom je vse bolj zabrisana (Difu-Berichte ..., 2002). To še posebej velja in je posebej opazno v mestih. Vse več dejavnosti se odvija tekom dneva, le da v temnem delu dneva nekoliko drugače, predvsem pa na drugih krajih. Vse več dejavnosti opravljamo v času, ki je bil pred desetletji namenjen počitku in družinskemu življenju. Vse več dejavnosti se iz dopoldneva prenaša v pozno popoldne ali zgodnji večer, vse več družabnih aktivnosti pa se prenaša v noč in na dneve ob koncu tedna. Število ljudi, ki so kot uporabniki ali izvajalci udeleženi v dejavnostih ponoči, se povečuje. Noč postaja vse bolj ekonomsko aktivno obdobje, s tem pa tudi kulturno in socialno raznoliko.

Kljub aktualnosti v nam dostopni literaturi nismo zasledili obravnave mesta ponoči. Tematika se pojavlja zgolj obrobno. Pohl (2009) nakazuje potrebo po spoznavanju 
mesta $\mathrm{z}$ vidika časa. Na obravnavano tematiko posredno napeljujejo sociologi, med njimi Lefebvre (2013), ki v delu Produkcija prostora razčlenjuje povezanost prostora in časa. Še najbližje obravnavani temi je Schwegmann (2016), ki v delu Nacht-Orte obravnava fenomenologijo noči in ekonomsko geografske vsebine, ki iz tega izhajajo . Prikaz je povsem teoretsko naravnan, na meji filozofsko antropološkega eseja. Zapis o mestu ponoči je prispevala tudi Body-Gendrotova (2011), vendar je njen opis zelo splošen, vsebinsko neartikuliran in konceptualno nedodelan. Zasledili smo še tri dela, ki prikazujejo nočno življenje v velemestih, Berlinu (Bretthauer, 1999), Londonu (Beaumont, 2015) ter primerjalno študijo Berlina, Pariza in Londona (Schlor, 1998) ob koncu 19. in v prvi polovici 20. stoletja. Mesto ponoči tako čaka tudi na celovito geografsko obravnavo.

Namen prispevka je pokazati področja in dejavnosti, ki vzpostavljajo mesto v nočnem času. Bolj kot prikazati nočno življenje izbranega mesta želimo pokazati novo vsebinsko področje geografije ter ob tem preveriti njen vsebinski domet.

\section{GEOGRAFSKI KONTEKST SPOZNAVANJA MESTA PONOČl}

V izhodišču spoznavanja mesta ponoči sta dva vidika: eden se nanaša na čas, drugi pa na območja, ki »živijo« ponoči.

\section{I Prostor in čas}

Čas je dimenzija prostora, čas je ujet v prostoru in v vsakem prostoru (kraju) je razvidna sled časa. Lefebvre je to označil kot »lokaliziranost« časa, kar pomeni, da so lastnosti prostora povezane s časom (obdobjem), ko določene dejavnosti potekajo (Lefebvre, 2013, str. 123). Pojmi kot so delovanje (v smislu zadovoljevanja potreb), razvoj, intenziteta pojava, vsebujejo časovno razsežnost, čeprav jih zaznavamo v prostoru. Še nekaj je pomembno: dogajanje $\mathrm{v}$ prostoru poteka $\mathrm{v}$ neenakem ritmu, $\mathrm{v}$ ciklih, saj se intenzivnost posameznega pojava spreminja tekom opazovanega obdobja, denimo noči. Na ta način se prostor in čas kažeta kot različna, vendar nedeljivo povezana. Noč »lokalizira« (ustvarja) kraje s posebno vsebino, kakršni v svetlem delu dneva ne nastajajo. Vendar je kljub zavedanju, da sta čas in prostor povezana, poznavanje prostora z vidika časa obsežnejše kakor poznavanje časa $\mathrm{z}$ vidika prostora. Ta del razmerja med prostorom in časom še čaka na poglobljeno obdelavo.

Drugo izhodišče so območja, kjer se dejavnosti pojavljajo. Čeprav ta vidik ni izključno povezan z nočjo, pa v obravnavani tematiki še posebej izstopa. Posamezna dejavnost se pojavlja $\mathrm{v}$ določenem delu mesta, ne kjer koli in samo $\mathrm{v}$ določenih časovnih obdobjih: pomembno je, da se dejavnost pojavlja s posebno socialno skupino uporabnikov oziroma obiskovalcev. Prostor, kjer se določena dejavnost pojavlja in je namenjena določeni socialni skupini ljudi, imenujemo kraj. V svetlem delu dneva se na taistem prostoru lahko pojavi druga dejavnost in druga socialna skupina. Zaključimo lahko: čas in kraj sta povezani kategoriji, čas ustvarja posebne kraje in jim daje posebno vsebino. Ponoči nastajajo kraji, ki so drugačni (in drugje) kot podnevi. Ti ugotovitvi še ne nakazujeta 
vsebine spoznavanja mesta ponoči, predstavljata pa vsebinsko-metodološki okvir za njihovo opredelitev. Za opredelitev vsebine je potrebno izhajati iz lastnosti noči, ki smo jih nakazali na začetku.

\subsection{Lastnosti noči v mestu}

V različnih delih noči prevzemamo različne vloge in počenjamo različne stvari. Tudi število dejavnosti in njihova intenzivnost se tekom noči spreminjata, $\mathrm{s}$ tem pa tudi število njihovih uporabnikov in število krajev, kjer se pojavljajo. Noč lahko pojmujemo tudi kot proces.

Noč ni enovita, temveč je strukturirana, razdeljena na obdobja. Že v davni preteklosti so ljudje členili dan, pa tudi noč. Rimljani so noč delili na 12 enot. V srednjem veku se je uveljavila delitev na tri dele: prvi del noči je bil namenjen počitku, v drugem delu noči so nakrmili živino, nekaj malega pojedli in pomolili, $v$ tretjem delu noči pa so počivaje pričakali jutro oziroma nov dan (Schnepel, 2016). Ljudje so verjeli, da jih v prvem delu noči spremljajo in opazujejo demoni, ki so z njimi prišli iz gozda; v drugem delu noči so demoni na delu, ljudje pa se jim zoperstavljajo, v tretjem delu noči pa jih demoni zapuščajo. Tudi v mestih opažamo, da se pojavnost in intenzivnost številnih aktivnosti tekom noči spreminjata, zato je mogoče razlikovati vsaj tri do štiri obdobja: pozno večerno obdobje, polnoč, trdo noč in zgodnje jutro.

Noč ustvarja kraje. V temnem delu dneva se odvijajo nekatere aktivnosti, ki jih čez dan ne srečamo. Številne med njimi se odvijajo na posebnih krajih, ki imajo tekom dneva drugačno funkcijo in drugačen značaj. Lahko pridobijo oznako »kraji nočnega življenja«, lahko so kraji, ki poudarjajo in ustvarjajo identiteto mesta; kraji, kjer poteka gospodarska dejavnost; lahko so kraji, kjer je zadrževanje manj varno in se jih zato mnogi prebivalci izogibajo. Kraje, ki so povezani s pojavom noči, lahko razvrstimo v številne skupine; v pričujoči obravnavi smo se omejili na naslednje:

- kraji potrošnje (trgovine, ekonomsko aktivna območja),

- kraji produktivnega dela (delo v industriji in storitvenih dejavnostih),

- kraji zabave in nočnega življenja,

- kraji nočne podobe mesta in

- kraji družbeno nesprejemljivega ravnanja

Noč je socialna kategorija. Za nekatere je noč čas počitka, priprava na nov delovni dan. Za mnoge je noč čas, ko je socialni nadzor manjši, ko lahko delujejo manj izpostavljeno, so manj na očeh. Zato se v tem času odvijajo dejavnosti, ki jih označujemo kot deviantne, družbeno nesprejemljive (kriminal, vandalizem, nasilje), vprašljive morale (prostitucija), pa tudi dejavnosti, ki pritegujejo posebne uporabnike (nočno življenje, zabava). Noč je obdobje, ko so aktivne nekatere socialne skupine, ki čez dan niso. To velja tako na strani povpraševanja kot ponudbe. $Z$ nočjo so povezane specifične vrednote, ravnanja, dogodki, ki so za svetli del dneva manj značilni in pogosti. Kadar koli govorimo o socialni funkciji prostora, je potrebno upoštevati tudi socialno sestavo akterjev oziroma ljudi, ki se na določenem območju nahajajo; sprašujemo se o socialnih lastnostih akterjev, 
krajih, kjer delujejo, vrsti delovanja ter številčnosti udeležencev. Poznavanje socialnih skupin in socialnih lastnosti prebivalcev, ki so dejavni v nočnem času, je pomemben vidik mesta ponoči.

Noč je čas številnih dejavnosti. Življenje v mestu se s temo ne konča. Mnoge dejavnosti resda prenehajo delovati, številne delujejo manj intenzivno, veliko pa je takih, katerih vrhunec je ponoči, saj se čez dan ne pojavljajo ali pa v omejenem obsegu. Noč je njihov čas in takrat dobijo dotični kraji in deli mesta poseben značaj. Zdi se, da število takšnih dejavnosti in krajev narašča. Naštejmo nekatere: zabava postaja vse bolj razširjena, diferencirana in raznolika. Nekoč je bila, vsaj v srednje velikih mestih, omejena na dneve ob koncu tedna, danes pa se odvija skoraj vse dni v tednu, na vse več krajih in z vse širšim občinstvom. Nakupovanje ponoči zapolnjuje prosti čas aktivnega dela prebivalcev, ki si po delovnem času želijo novih doživetij. Številne športne prireditve se prav tako začenjajo v zgodnjem delu noči, ne pa popoldne, kot je bilo običajno. Tudi na področju kulture se vse več prireditev začenja v zgodnjem delu noči ali pa se zavleče v noč. Številne kulturne ustanove odpirajo vrata obiskovalcem v prvem delu noči; s projektom »Poletna muzejska noč« nagovarjajo prireditelji prebivalce večjih mest k drugačnemu, nenavadnemu doživetju ob obisku muzejev (Poletna muzejska ..., 2016). Veliko dejavnosti, katerih namen je zagotavljanje varnosti ljudi in imetja, je še posebej intenzivno v nočnem delu dneva in tudi njihovo število narašča. Ob tem narašča tudi število uporabnikov storitev v nočnem času. Delo v nočni izmeni v industrijskih obratih je postalo le eno v vrsti mnogih, ki uporabljajo noč v ekonomske namene.

Noč je obdobje produkcije, menjave dobrin, dogajanja ponoči imajo ekonomsko razsežnost. Ne gre le za nočno življenje oziroma zabavo $\mathrm{v}$ širšem pomenu besede. V sodobnem kapitalizmu je mogoče ekonomske učinke ustvariti le še s podaljševanjem ekonomsko aktivnega obdobja. Merodajen je prilagodljiv, prožen delovni čas, s tem povezana ponudba dobrin, nove oblike dela in sprememba družbenih vrednot. Podaljševanje obratovalnega časa trgovin $\mathrm{v}$ začetek noči, vse pogostejše nakupovanje ponoči, vse bolj številne prireditve v nočnem času, vse bolj običajen začetek prireditev, ki se pomika proti 22. uri, številni proizvodni obrati, kjer delo poteka preko noči, vse to so novodobne oblike nočnega življenja mesta, označimo jih lahko kot »industrializacijo nočnega življenja«. Nekdaj izključno dnevna opravila postajajo tudi nočna opravila, dan vdira v noč. Podaljševanje socialne in gospodarske aktivnosti (dejavnosti) $\mathrm{v}$ temni del dneva ustvarja posebne kraje, ki imajo pogosto posebno identiteto in poseben pomen. Ne nazadnje je s tem povezanih veliko poklicev in delovnih mest na področju storitev, oblikovanja, varovanja. Področje estrade, umetnosti in gostinstva oziroma kulinarike je le manjši del »ekonomije fascinantnosti«, katere čas in prostor sta ponoči (Schwegemann, 2016, str. 138).

Noč oblikuje kraje in s tem podobo mesta. Odsotnost naravne svetlobe nadomešča umetna svetloba, ki ustvarja drugačno podobo mesta; kar ni osvetljeno, tega ne vidimo, ne obstaja. Že v tem se skriva obsežen vir spoznanj o mestu ponoči, o njegovi »nočni in dnevni identiteti«. S premišljeno osvetlitvijo je mogoče doseči posebno vzdušje, kakovosten ambient, ki posamezne kraje naredi privlačne za obiskovalce. Posebno vzdušje je rezultat noči, ki omogoča posebno osvetlitev. Med številnimi načini osvetljevanja sta dva, tako imenovano usmerjeno in pritajeno osvetljevanje, ob katerih grajene strukture 
izstopajo v novi podobi (Drozg, 2011). Svetloba (poleg osvetljevanja objektov in ulic) je kot barvni svetlobni snop vidna tudi sama. Vzdušje, ki ob tem lahko nastane, vzpostavlja zaključene ambiente, prostorske ureditve, ulice in trge, ima izrazito lokalni značaj. Zaradi kulturnega in simbolnega naboja vzbujata svetloba in osvetljevanje čustveno in duhovno dojemanje prostora, ustvarjata »drugo« resničnost (Hasse 2010, str. 21), zaradi česar mesto ponoči dojemamo drugače kot podnevi.

Če skušamo povedano formulirati v obliki vprašanj, ki razkrivajo mesto ponoči in predstavljajo vsebinski okvir spoznavanja in interpretacije, so ta naslednja:

- zaradi katerih dejavnosti živi mesto ponoči, kje so kraji teh dejavnosti;

- kolikšen del noči, kako dolgo so kraji aktivni, kako je noč strukturirana;

- katere socialne skupine so dejavne ponoči in na katerih krajih (relevantno je tudi število ljudi oziroma obiskovalcev, ki se na posameznih krajih zadržujejo);

- kakšni so kraji, ki ustvarjajo podobo mesta ponoči;

- kakšna je topografija mesta ponoči, razmestitev krajev, prostorski vzorec, ki ob tem nastaja?

\section{KAKO SPOZNAVATI MESTO PONOČI - METODA DELA}

Opredeljene kraje nočnega dogajanja smo skušali podkrepiti in prikazati z empiričnimi podatki. Ključni pri tem so podatki o dejavnostih in krajih, ki delujejo ponoči ter delovni čas gospodarskih subjektov. Upoštevali smo kraje, kjer se dejavnost odvija med 20. uro zvečer in 5. uro zjutraj. Da 20 . ura v povprečju še najbolje označuje začetek noči, vsaj v mentalnem smislu, navajajo tudi avtorji spletne strani s pomenljivim naslovom Stadt nach acht (mesto po osmi; Stadtnachacht.de, 2016). Lokacijo posamezne dejavnosti in delovni čas, na primer gostinskega lokala, smo pridobili na spletu, in sicer z iskanjem po ključnih besedah (bar, gostišče, bistro, bife, diskoteka, Maribor; obdelali smo okoli 200 zadetkov) ter s kartiranjem na terenu, ko smo tudi preverili in popisali še delovni čas. Terensko delo smo opravili od julija do oktobra leta 2016. Podatke o gospodarskih subjektih, ki delujejo v nočnem času, smo pridobili na Štajerski gospodarski zbornici in v Gospodarski coni Tezno, nekaj pa z vprašalnikom, ki smo ga poslali gospodarskim družbam, za katere smo predpostavili, da delujejo tudi v nočnem času. Podatke o kaznivih dejanjih smo pridobili iz uradnih evidenc Policije.

Pri posameznih vsebinah je bilo potrebno podatke o vrsti dejavnosti, lokaciji in delovnem času dopolniti še s številom obiskovalcev (udeležencev) in starostno sestavo (na primer na krajih zabave, krajih dela, krajih oskrbe). Te podatke smo pridobili s štetjem obiskovalcev in anketiranjem lastnikov gostinskih lokalov, kinodvoran in kulturnih prireditev. Zanimalo nas je število obiskovalcev na določenem kraju $v$ obdobju ene ure oziroma število obiskovalcev prireditve $\mathrm{v}$ nočnem času ter starostna sestava (po velikih starostnih skupinah). V krajih oskrbe smo ugotavljali število obiskovalcev med 20. in 21. uro, na krajih zabave pa med 20. in 21. uro, med 23. in 24. uro ter med 1. in 2. uro oziroma pred začetkom prireditve. Štetje na različnih krajih oskrbe smo izvedli štirikrat, na krajih zabave dvakrat, število obiskovalcev prireditev pa smo beležili šestkrat. S temi podatki je mogoče utemeljiti deljenost noči na več obdobij, saj se razlikujejo po številu 
obiskovalcev. Razlikovali smo kraje, ki živijo vso noč, tiste, ki so aktivni samo v prvem delu noči (do 22. ure), ter tiste, ki delujejo do druge ure zjutraj. Posebna kategorija so kraji, kjer se aktivnosti pojavljajo občasno, ob praznikih in posebnih dogodkih. Omeniti je potrebno še eno okoliščino, ki vpliva na sliko mesta ponoči: v topli polovici leta in ob koncu tedna je noč v mestu drugačna kakor v hladni polovici leta in ob delavnikih.

Kraje, kjer je podoba mesta ponoči posebej slikovita, smo ugotavljali s kartiranjem osvetljenih objektov, vrste in namembnosti okoliškega prostora. Glede na način osvetlitve in urbanost okolice smo ocenili, ali osvetljeni objekti in neposredna okolica vzpostavljajo kakovosten mestni ambient. Kraje smo prikazali še kartografsko, s čemer smo pridobili vpogled v prostorski vzorec obravnavanih vsebin.

\section{TOPOGRAFIJA MESTA PONOČl}

Mesto si lahko predstavljamo kot preplet številnih in najrazličnejših krajev, kjer potekajo različne aktivnosti in kjer se zadržujejo pripadniki različnih socialnih skupin. Ponoči je število krajev manjše kot podnevi, vendar je število obiskovalcev na krajih pogosto večje kakor podnevi. V nadaljevanju prikazujemo kraje v Mariboru, ki živijo ponoči.

\section{I Kraji potrošnje}

Večina trgovin v Mariboru posluje do 19. ure, razen v nakupovalnih središčih, kjer je delovni čas do 21. ure in slednje lahko pojmujemo kot kraje potrošnje ponoči. Tovrstni kraji potrošnje presegajo zgolj oskrbno funkcijo, saj so v enaki meri tudi socialni prostori, kraji srečevanja in družabnega življenja. Pomenljiva je socialna struktura obiskovalcev nakupovalnih središč v večernem/nočnem času. V nakupovalnem središču Qulandia smo 9. septembra 2016 med 20. in 21. uro zabeležili 435 obiskovalcev, od tega je bilo 60 do $65 \%$ mladih in obiskovalcev srednjih let, slaba četrtina starejših obiskovalcev in okoli $10 \%$ otrok. Povsem drugačna je bila starostna sestava obiskovalcev istega dne v dopoldanskih urah, ko je delež starejših občanov znašal med 35 in 40 \%. Izpostaviti je potrebno še poseben kraj potrošnje v središču mesta, kjer smo med 20. in 21. uro našteli več kupcev kot istega dne med 10. in 11. uro. Starostna sestava kupcev zvečer je zelo zgovorna: 80 \% mladih in mlajših srednjih let, ki se na poti z delovnega mesta proti domu ustavijo še v trgovini z živili. Ti kraji potrošnje delujejo v prvem delu noči. Tudi v predprazničnih dneh, ko je obratovalni čas nekaterih trgovin podaljšan, ta ne traja dlje kot do 22. ure. Največ nakupovalnih središč je na robu mesta ter na robu širšega središča, kraji potrošnje ponoči so enakomerno razporejeni po območju mesta.

Poleg nakupovalnih središč so kraji potrošnje še nekateri bencinski servisi, kjer ponudba blaga presega oskrbo z gorivom. Predvsem v topli polovici leta so tudi kraji srečevanja mlajše populacije. Ti kraji potrošnje so aktivni preko celotne noči, vendar kot kraji zabave zgolj v prvem delu noči, preden se obiskovalci, večinoma mladi, odpravijo drugam. Kraji potrošnje delujejo preko leta $\mathrm{v}$ istem časovnem ritmu, ne spreminjata se niti število niti struktura obiskovalcev. 
Slika 1: Shematski prikaz krajev potrošnje.

Figure 1: Places of retailing and consumption.

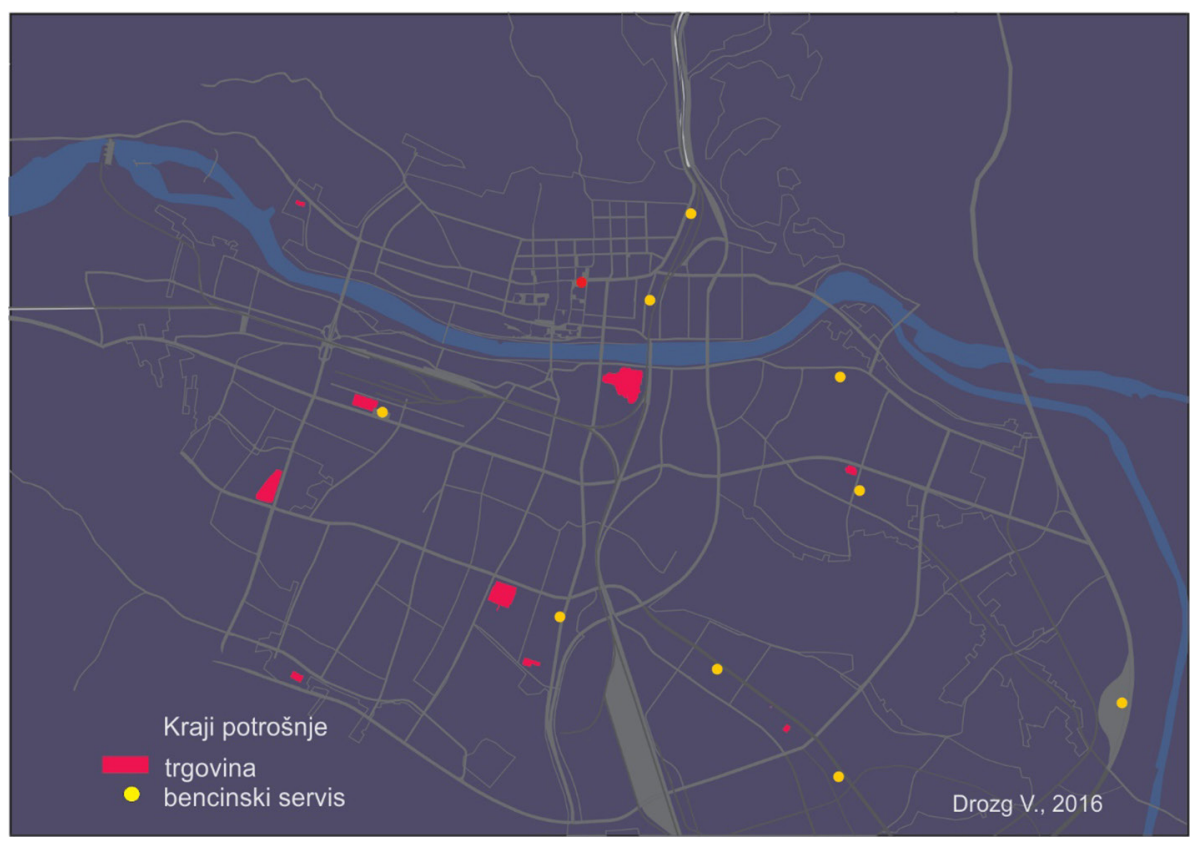

Viri/Sources: terensko delo, 2016; kartografske podlage: Mestna občina Maribor, 2014; spletne strani trgovskih organizacij, 2016.

\subsection{Kraji dela}

Med kraje dela smo uvrstili proizvodne obrate ter storitvene službe (ustanove) v širšem pomenu besede, ki skrbijo za varnost prebivalcev, na primer policijske postaje, bolnice, gasilske domove, reševalne postaje, pošto, kjer opravljajo plačano delo v nočni izmeni. Ti kraji so razmeščeni po celotnem mestu, veliko jih je v industrijskih conah, nekaj pa v širšem središču mesta. Večinoma gre za posamične lokacije, ne pa večja, sklenjena območja, ki bi izstopala v prostoru. Delo ponoči poteka na številnih lokacijah, v delo ponoči je vključenih po grobi oceni med 3000 in 4000 ljudi (ocena Gospodarske cone Tezno, september 2016), kar je približno $10 \%$ aktivnega prebivalstva mesta. O socialni sestavi zaposlenih v nočnem času nimamo zanesljivih podatkov. Iz vrste proizvodnih obratov, kjer poteka delo v nočni izmeni, pa sklepamo, da gre večinoma za proizvodne delavce. Delo ponoči je zgolj občasno, povezano s proizvodnim procesom v delovni organizaciji. Drugačne so razmere v ustanovah in storitvenih dejavnostih, česar pa ne moremo podkrepiti z numeričnimi podatki. Kraji dela so aktivni preko celotne noči ali vsaj velik del noči. 
Slika 2: Shematski prikaz krajev dela.

Figure 2: Workplaces in the city of Maribor at night.

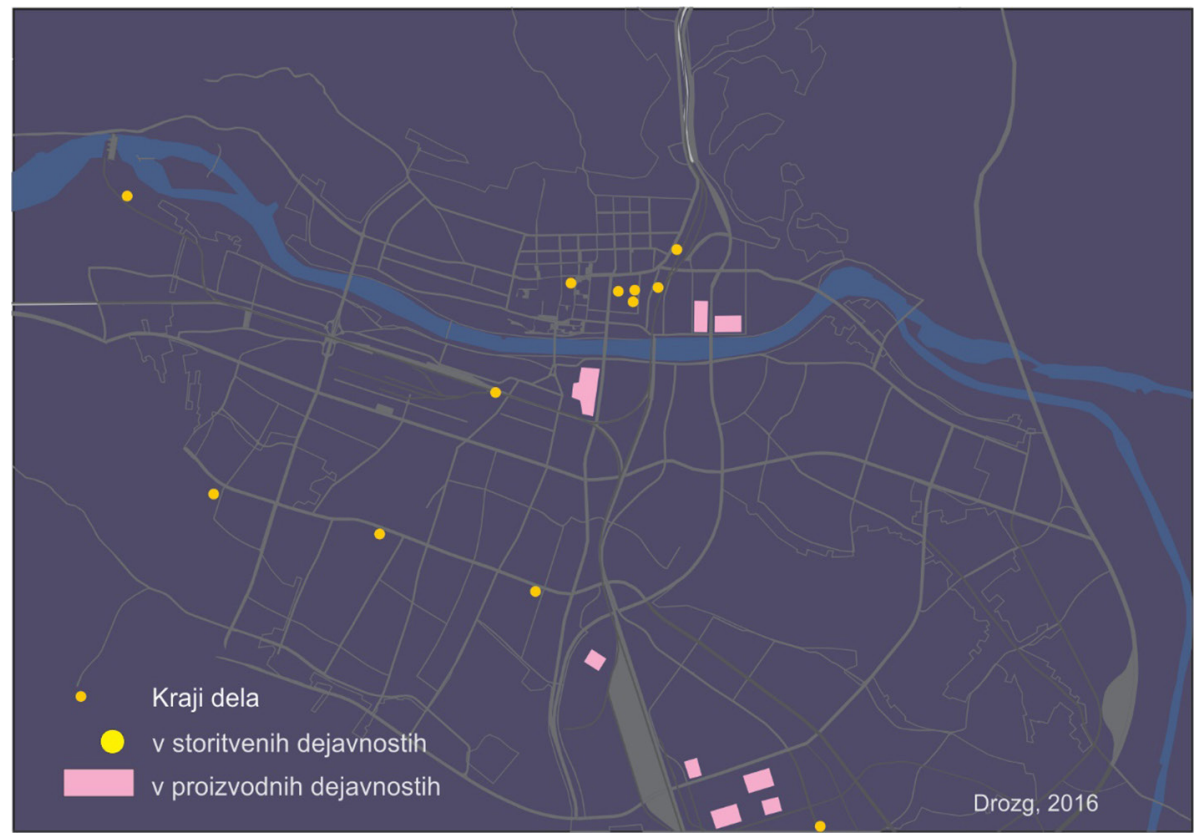

Viri/Sources: terensko delo, 2016; kartografske podlage: Mestna občina Maribor, 2014.

\subsection{Kraji zabave in nočnega življenja}

Kraje zabave smo razdelili v tri skupine. Prvo skupino tvorijo kraji institucionalizirane zabave, kjer se občinstvo zabava ob predstavah nastopajočih (gledališke, filmske in glasbene predstave); pomemben razpoznavni element teh krajev je dvorana $\mathrm{z}$ odrom. Ta oblika zabavnega življenja se odvija na številnih lokacijah, ob določenih dnevih v tednu, v prvem delu noči, približno do 22. ure ali do polnoči. Večina obiskovalcev je srednjih let, med njimi je veliko seniorjev. V drugi skupini so kraji, kjer ljudje sami poskrbijo za zabavno vzdušje. V to skupino sodijo gostinski lokali, diskoteke in bari. Večina njih obratuje do 22. ure, nekaj pa tudi do jutranjih ur, predvsem ob koncu tedna. To so lokali z glasbo (pogosto živo) in plesiščem. Tovrstnih krajev je največ v središču mesta, nekaj pa tudi na območju širšega središča. Posebej obiskani so gostinski lokali na Lentu, kjer jih največ deluje do jutranjih ur, v Poštni ulici ter na Grajskem trgu. Predvsem Lent in Poštno ulico je mogoče označiti kot kraje nočnega življenja. Pomemben del nočnega življenja je glasba, še posebej, če je živa, kar pritegne največ obiskovalcev. 10. 9. 2016 smo na Grajskem trgu med 22. in 23. uro našteli 63 oseb, kar je skoraj polovico več kot na isti lokaciji med 20. in 21. uro (in dvakrat manj kot med 10. in 11. uro dopoldan). Na Poštni ulici pa smo 20. avgusta 2016 med 20.00 in 20.15 
našteli 189 obiskovalcev, med 23.00 in 23.15 že 386 oseb, kar je 10-krat več kot med 11.00 in 11.15 opoldan, med 2.00 in 2.15 pa 77 obiskovalcev. Slednje potrjuje, da gre za del mesta, ki zaživi šele ponoči. Starostna sestava obiskovalcev je povsem na strani mladih in mlajšega dela starostne skupine srednjih let (do 40 let). Podoben kraj zabave in nočnega življenje je ob univerzitetnem kampusu na Koroški cesti, ki zaživi šele po 22. uri, ob 3. uri zjutraj pa se nočno življenje preseli v zasebne prostore. Tudi na tem kraju nočno življenje spodbuja glasba, pogosto »živa«. Tretja vrsta krajev zabave so prizorišča javnih prireditev, ki jih je ob tako imenovani festivalizaciji mest vedno več. Sicer so prireditve in koncerti na prostem občasni dogodki, ki pa pritegnejo veliko število obiskovalcev, in običajno trajajo do polnoči. Kraji občasnih prireditev so v središč mesta, sestava obiskovalcev pa je zelo raznolika.

Kraje zabave je mogoče razvrstiti tudi po pogostosti, in sicer na kraje vsakodnevne zabave, tedenske in občasne. V Mariboru je krajev vsakodnevne zabave sicer največ, saj je gostinskih lokalov, kamor smo tovrstne kraje uvrstili, razmeroma veliko. Več nočnega življenja se odvija ob koncu tedna v lokalih z glasbo ter v krajih institucionalizirane zabave. Na krajih občasnega nočnega življenja se zbere veliko ljudi, vendar je časovni ritem teh dogodkov redek.

Slika 3: Shematski prikaz krajev zabave.

Figure 3: Places of entertainment.

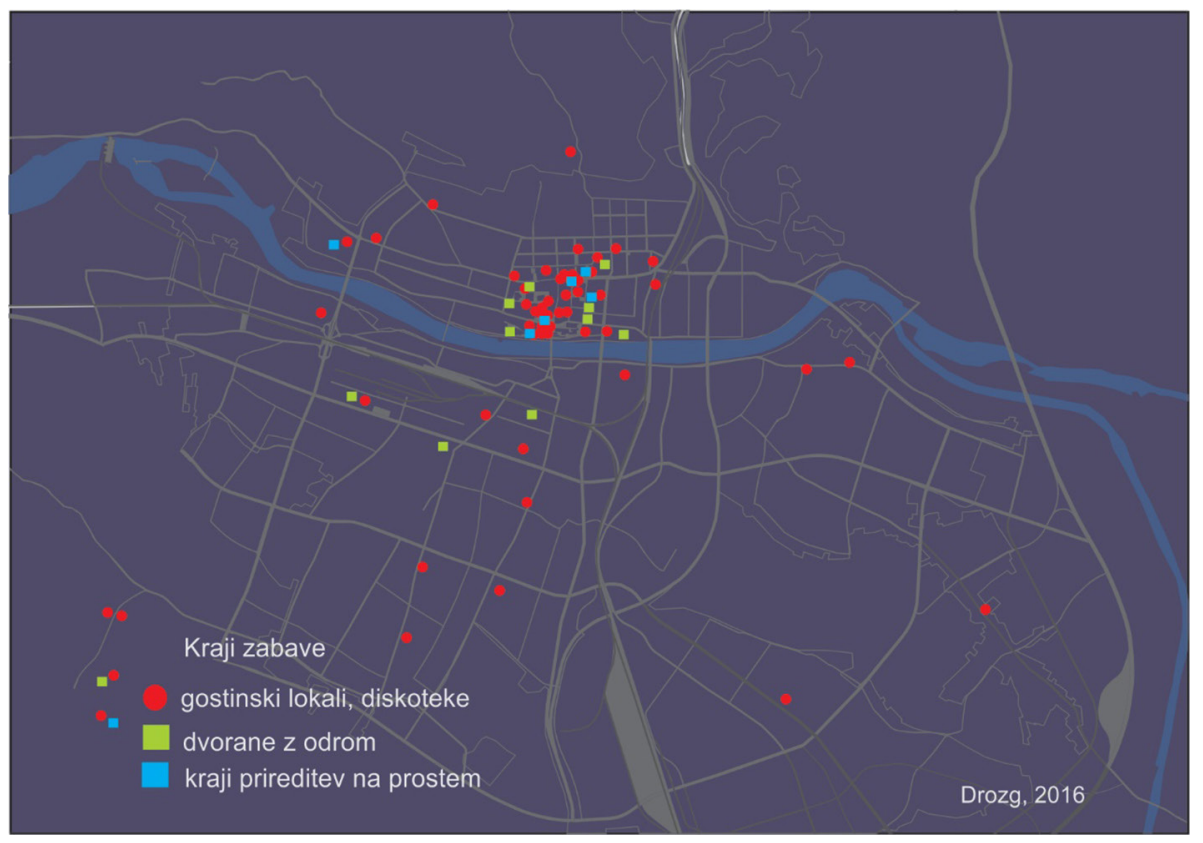

Viri/Sources: terensko delo, 2016; kartografske podlage: Mestna občina Maribor, 2014. 


\subsection{Kraji nočne podobe mesta}

Nočna podoba mesta je odraz zavedanja o potrebni estetizaciji bivalnega okolja. Ustrezna osvetlitev zgodovinsko pomembnih objektov, objektov, ki izkazujejo gospodarsko in duhovno moč mesta ter objektov, ki obeležujejo kraje posebnega pomena, je znak kulturnega okolja, vzpostavlja pozitivno vzdušje, oblikuje kakovostne ambiente in nakazuje identiteto mesta. Pri tem sta merodajna predvsem usmerjena in pritajena vrsta osvetlitve ter namembnost in pomen bližnjih objektov. V Mariboru so osvetljene predvsem monumentalne stavbe iz 19. in začetka 20. stoletja, v katerih delujejo javne ustanove. Poleg teh so osvetljeni še sakralni objekti in sakralni spomeniki. Razmestitev osvetljenih objektov je zelo neenakomerna, večina jih je v mestnem središču v severnem delu mesta. Osvetljeni objekti z bližnjo okolico vzpostavljajo kakovosten urbani ambient, kar predstavlja identiteto mesta. Barva svetlobnega snopa je klasično rumena, le ob izjemnih dogodkih je uporabljena drugačna, bolj nekonvencionalna osvetlitev. Osrednji prireditveni trg v mestnem središču je primer izvirnega načina osvetljevanja, kjer prav raznobarvna svetloba ustvarja kakovosten ambient. Pritajena osvetlitev mostov čez Dravo poudarja položaj mesta ob reki, osvetljeni mestni trgi pa poudarjajo vtis urbanosti.

Slika 4: Shematski prikaz kraji nočne podobe mesta.

Figure 4: Places that embody the night image of the city.

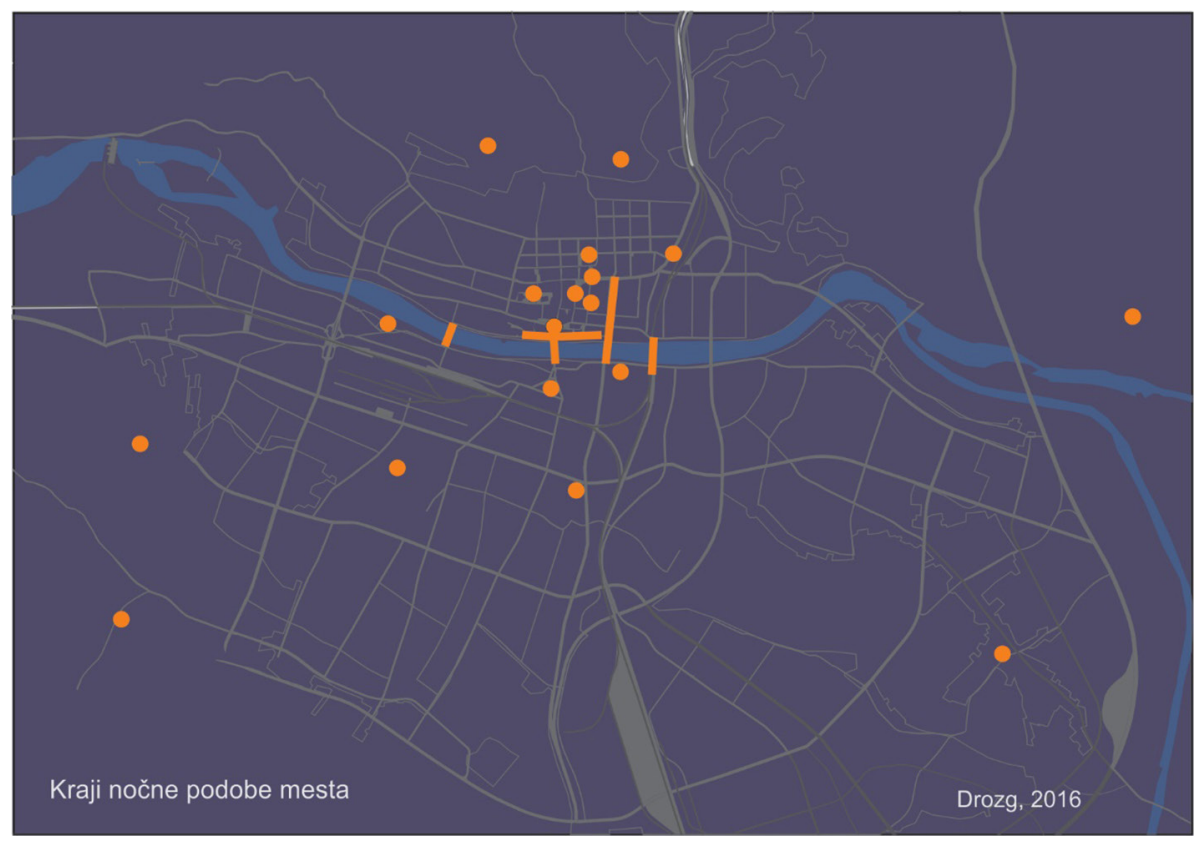

Viri/Sources: terensko delo, 2016; kartografske podlage: Mestna občina Maribor, 2014. 
S pritajeno svetlobo osvetljena krožišča in prehodi za pešce pa prinašajo poleg varnosti še novo podobo prometnic. Omeniti je potrebno še osvetlitev obeležij in spomenikov, ki prav tako ustvarjajo kraje nočne podobe mesta. Tudi teh je največ v mestnem središču. Prostorski vzorec kakovostnih ambientov, nastalih z osvetljevanjem, je zelo neenakomeren; v nekaterih delih mesta nočno podobo ustvarjajo samo ulične svetilke oziroma t. i. nevtralna osvetlitev. Največ krajev nočne podobe je v srednjeveškem in meščanskem delu mesta, industrijska dediščina in stanovanjska območja pa še niso nadgrajena v kraje, ki bi s posebnim vzdušjem bogatili nočno podobo mesta.

\subsection{Območja delikventnega vedenja}

Noč in s tem povezana slabša vidnost, zmanjšan socialni nadzor in manjše število ljudi na javnih mestih, lahko spodbudi v ljudeh neprimerno in kaznivo vedenje. Noč je čas posebnih dejanj, posebnega vedenja, kakršno je čez dan skrito, zatajeno, očem nevidno.

Slika 5: Shematski prikaz števila kršitev javnega reda in miru po mestnih četrtih v času med 20. uro zvečer in 8. uro zjutraj (podatki so za obdobje od 1. 1. 2015 do 31. 3. 2016).

Figure 5: Number of violation of public order according to town districs in the period between 8 a.m. and 8 p.m. (data relevant for the period from 1 January 2015 to 31 March 2016).

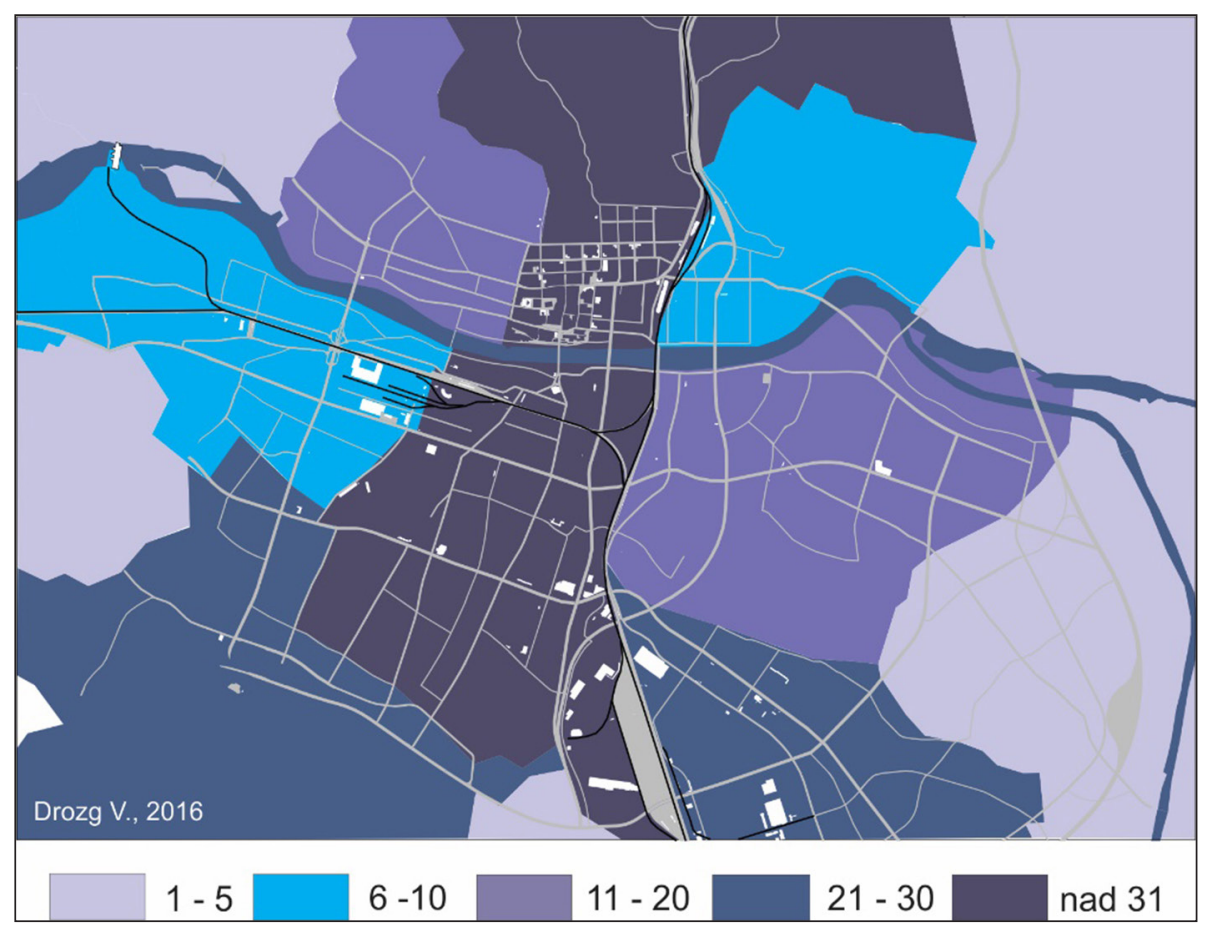

Viri/Sources: Uradne evidence Policije, 2016; kartografske podlage: Mestna občina Maribor, 2014. 
Za prikaz tega vidika noči smo uporabili podatke Policijske postaje Maribor o številu kršitev javnega reda in miru ter podobnih kaznivih dejanjih, recimo o vlomih (v času med 20. uro zvečer in 6. uro zjutraj). Podatki se nanašajo na obdobje od 1. januarja 2015 do 31. marca 2016 (Uradne evidence Policije, 2016). Število intervencij policijske patrulje tekom dneva in noči se bistveno ne razlikuje; podnevi je Policija opravila 225 intervencij, ponoči pa 214. Razlika je v strukturi oziroma vzrokih za intervencijo. V nočnih urah je policija posredovala 131- krat zaradi kršitve javnega reda in miru, podnevi pa 70- krat. Za veliko ljudi je noč še vedno čas slabšega samonadzora.

Prostorska razporeditev policijskih intervencij pokaže, da je bilo največ kršitev javnega reda in miru v delih mesta, kjer je gostota krajev zabave največja. V središču mesta je kršitev največ, le nekaj manj jih je v robnih predelih, kjer so posamezni kraji zabave in kraji prireditev. V stanovanjskih predelih mesta je bilo kršitev precej manj, pa tudi struktura kršitev se nekoliko razlikuje. Na krajih zabave je javni red in mir najpogosteje kršen zaradi nasilja in vandalizma, $v$ stanovanjskih soseskah pa je vandalizem najpogostejši vzrok policijskih intervencij. Upoštevati je potrebno, da se podatki nanašajo na celotno območje mestnih četrti, največ delikventnih dejanj pa je v bližini krajev zabave.

\section{SKLEP}

Spoznavanje mesta v nočnem času predstavlja nov pogled na sicer dobro poznan del prostora. Med mestom podnevi in mestom ponoči je veliko vzporednic in podobnosti, tisto, v čemer se pogled na mesto ponoči razlikuje od običajnega, je časovna razsežnost (prostora) ter vrsta dejavnosti, ki jih noč prinaša v življenje ljudi. Druga posebnost spoznavanja mesta ponoči je omejenost oziroma osredotočenost na posamezne kraje; ekonomsko in socialno aktivno ni celotno območje mesta in celotno noč, temveč zgolj manjša območja (kraji), kjer so locirane dejavnosti, ki ponoči pritegnejo večje število ljudi. To niso zgolj kraji zabave, relevantni so tudi kraji dela, kraji potrošnje, kraji, ki zaradi svoje oblikovanosti in posebnega vzdušja pritegujejo večje število obiskovalcev, tudi kraji delikventnega vedenja. Mesto je polivalenten pojav, v katerem je veliko lepega, pa tudi veliko animaličnega, čemur služi noč kot odlična kulisa. Prav zaradi raznovrstnih dejavnosti in krajev, ki nastajajo ponoči, je spoznavanje socialne strukture še kako relevantno, saj se pokaže, da je mlajši del populacije najštevilnejši le na krajih zabave, slednji pa so samo ena od vsebin nočnega dogajanja v mestu.

Mesto ponoči ima veliko obrazov - noč je čas posebne ekonomije, posebnih socialnih pojavov, drugačne podobe. Pričakujemo lahko, da bodo te teme slej ko prej vključene v urbanistično urejanje in analize gospodarskega razvoja, s tem pa tudi predmet spoznavanja številnih ved. Upamo, da bo med njimi tudi geografija. 


\section{Literatura in viri}

Beaumont, M., 2015. Nightwalking: A Nocturnal History of London. London, Verso, 496 str.

Body-Gendrot, S., 2011. Nights in the Global City. V: Bridge, G., Watson, S. (ur.). The New Blackwell Companion to the City. Oxford, Wiley-Blackwell, 2011, str. 606-616.

Bretthauer, B.,1999. Die Nachtstadt: Tableaus aus dem dunklen Berlin. Frankfurt am Main, Campus Verlag, 220 str.

Difu-Berichte 2/2002 - Alles zu jeder Zeit? - Die Städte auf dem Weg in die kontinuierlicheAktivität, 2002. https://difu.de/publikationen/difu-berichte-22002/alles-zu-jeder-zeit-die-staedte-auf-dem-weg-in-die.html (citirano 7. 9. 2016).

Drozg, V., 2011. Osvetljevanje kot predmet geografskega spoznavanja mest (na primeru Kopra). Revija za geografijo, 6-1, str. 93-102.

Hasse, J., 2012. Atmosphären der Stadt. Aufgespürte Räume. Berlin, Jovis Verlag, 190 str. Lefebvre, H., 2013. Produkcija prostora. Ljubljana, Studia Humanitatis, 308 str.

Pohl, T., 2009. Entgrenzte Stadt, Räumliche Fragmentierung und zeitliche Flexibilisierung in der Spätmoderne. Bielefeld, transcript Verlag, 390 str.

Poletna muzejska noč. Program 2016. 2016. URL: http://www.tms.si/PMN/?page_id=67 (citirano 31. 6. 2016).

Schlor, J., 1998. Nights in the Big City: Paris, Berlin, London, 1840-1930. London, Topographics, 352 str.

Schnepel B., 2016. Strangers in the Night: The Making and Unmaking of Differences from the Perspective of an Anthropology of the Night. URL: http://wcms.itz.uni-halle. de/download.php?down=1630\&elem=1970176 (citirano 16. 8. 2016).

Schwegmann, R., 2016. Nacht-Orte. Eine kulturelle Geographie der Ökonomie. Bielefeld, transcript Verlag, 176 str.

Stadtnachacht.de, 2016. URL: http://www.stadtnachacht.de (citirano 7. 9. 2016).

Uradne evidence Policije. Policijska postaja Maribor, 2016.

\section{THE CITY AT NIGHT (THE CASE OF MARIBOR, SLOVENIA)}

\section{Summary}

The night is becoming a more economically, socially and culturally active part of the day. More and more activities take place throughout the whole day, though at night, they take place differently and in other locations. More activities are being done at times that decades ago would have been set aside for rest and family life. An increasing number of activities have shifted to the night and weekends. The number of people taking part in these night activities, be they users or providers, is growing too. It is becoming an economically very active part of the day, resulting in cultural and social diversity. Characteristics of the city at night are shaped by numerous elements of the night.

The night is not a uniform period, rather, it is structured and divided into specific periods. We can observe that the frequency and intensity of many urban activities change 
over the course of the night; it is therefore possible to distinguish at least three to four distinct periods: late evening, midnight, late night and early morning. The night is both a process and creator of places. Numerous activities are taking place at specific locations that have a different function along with a different character during the day. They can become known as "places of night life", they can be places that accentuate and shape the identity of a city, places of economic activity, places that are less safe and therefore avoided by many residents. Places, associated with the onset of the night, can be divided into following groups:

- Places of retailing and consumption (shops, economically active areas),

- Workplaces (in industrial and service sectors),

- Places of entertainment and nightlife,

- Places that embody the night image of the city and

- Places of socially unacceptable behaviour.

The night is a social category. For some, it is a time of rest and preparation for a new working day. For many, it is a time of reduced social control. A time for activities, which are labelled as deviant and socially unacceptable (crime, vandalism, violence), or those of questionable moral standings (prostitution). Then there are activities that attract a specific clientele (nightlife, entertainment). Certain social groups, not active during the day, become active during the night. Specific values, behaviours and events are linked to the night time, which are less characteristic and common during daytime.

Production and exchange of goods also take place at night; night activities therefore have an economic dimension. Not everything is about night-life or entertainment, per se. In modern capitalist times, further economic surpluses are only possible by extending periods of economic activity. Extending the opening hours of shops into the early hours of the night, allowing for shopping as late as midnight, organising many events in the night time, pushing the start of events to 22:00 hours, introducing night shifts for industrial workers; all these are modern forms of night life in a city that can be described as "industrialisation of night life". The extension of social and economic activities into the dark part of the day creates specific places that often hold a special meaning and have a particular identity.

The night shapes cities and through this also influences the city's image. An absence of natural light is replaced by artificial light which creates a new image of the city, also leaving parts unilluminated, things and places that do not exist because we cannot see them. With well thought-out illumination, one can achieve a special atmosphere, a quality ambience that attracts visitors to particular places. Light and illumination invoke emotional and spiritual perceptions of space, creating "the other" reality. Thus, the city is perceived differently at night than during the day.

Questions that reveal the city at night by serving as a conceptual framework for interpretations on this topic are:

- Which activities make cities active and bring them to life at night; where do these activities occur?

- What proportion of the night is active, how long do places remain active and how is the night structured? 
- Which social groups are active at night and in which locations (also relevant is the number of people or visitors that frequent certain places)?

- What are places that embody the night image of the city like?

- What is the topography of the city at night, distribution of places, and spatial pattern which arises at night?

Below, we have attempted to shed light on places formed by economic activities and practices of social groups of users at night. The example looks at the Slovenian city of Maribor. Maribor is a medium-sized city, though despite its limited size, it is still possible to find many places that are alive also during the night. Between 3000 and 4000 people, almost a tenth of the active working population, are employed in different places of work. A lot of people, particularly young people, flock to places of consumption, generally shopping malls, in the earlier hours of the night. The most diverse places are those devoted to entertainment. As well as those catering to the older population, entertainment places with live music give the city its signature feeling, as they live late into the night and take over several streets in the medieval part of the city. The image of the city at night also speaks of the night as a specific time of the day when the city takes on a different look. Special lighting of public buildings and markets creates an attractive ambience, which cannot be experienced during the day. The night is also a time of increased socially inappropriate behaviour. In Maribor, such places are mainly in the vicinity of places of entertainment. 